\title{
PSEUDOPLANKTON: HITCH-HIKERS THROUGH TIME OR STUCK IN THE MUD?
}

KAUFFMAN, Erle G., *MEYER, Christian A., VILLAMIL, Tomás, and HARRIES, Peter J., Department of Geological Sciences, CB-250 University of Colorado, Boulder, CO 80309-0250, USA

Pseudoplanktic life modes have typically been invoked to explain the presence of abundant fossils belonging to normally low-oxygen intolerant taxa within oxygendeficient black shales facies (e.g., bivalves, crinoids, barnacles, serpulid worms, brachiopods, gastropods, bryozoans, foraminifers, corals, hydrozoans, and sponges). The same explanation has been used for exceptional paleobiogeographic distribution of benthic species. However, detailed paleoecologic, population, and taphonomic analyses of numerous black-shale biotas in conjunction with recently published models for oxygen-deficient basins suggests that this hypothesis is no longer required to explain the distribution of these taxa in supposedly non-viable habitats. Actual examples that could be interpreted as evidence for pseudoplanktic life habit (i.e., colonization on both sides of ammonites) are very rare. For example, less than $2 \%$ of the encrusted ammonites $(\mathrm{N}=1240)$ in the Jurassic Posidonienschiefer show pseudoplanktic colonization patterns. These could be interpreted as flipped specimens within the benthic zone. The remainder are stable "shell-island" substrates with ammonites (and large bivalve shells) colonized on one side only. Most logs believed to be colonized on the lower surface by bivalves and/or crinoids in floating position actually have evidence for benthic encrustation on the tops and sides of the logs, and have obvious current shadows of dead shells.

The data show that: 1) the abundance of these taxa greatly exceeds the expectations of pseudoplanktic rain as well as the number of potential hosts; 2) they commonly occur as short-term event communities rather than as the normal populations expected of continuous pseudoplanktic rain; 3) specimens are commonly found in epibenthic life position; 4) their occurrence patterns show strong facies control usually reflecting benthic oxygen gradients; 5) many preserve a large prodissoconch or protoconch suggesting a long-term planktotrophic larval stage. Most of these "pseudoplanktic" groups appear to have had a benthic life habit .

Moreover, most oxygen-deficient environments disappeared by the end of the Cretaceous along with some of the dominant pseudoplanktic taxa. Drifting logs and seaweeds are common today, but generally lack specific "pseudoplanktic" faunas, with the exception of boring bivalves, gooseneck barnacles, serpulid worms, and bryozoans. Epibenthic bivalves and crinoids are very rare to absent on potential "pseudoplanktic" hosts in modern seas, yet are the main groups of organisms designated as pseudoplankton in the fossil record. 